\title{
SERVIÇOS DE INFORMAÇÃO E O 'USUÁRIO INTERNO': NECESSIDADES DE COMPETÊNCIAS INFORMACIONAIS
}

\section{INFORMATION SERVICES AND THE 'INTERNAL USER': INFORMATIONAL SKILLS REQUIREMENTS}

\author{
Micarla do Nascimento Gomes ${ }^{1}$ \\ Claudialyne da Silva Araújo ${ }^{2}$
}

\begin{abstract}
RESUMO
Descreve a busca e uso da informação por parte dos usuários como sendo uma das motivações das bibliotecas para evoluir os serviços por ela prestados, seja na adaptação ou reestruturação de sua missão. Destaca que atualmente as bibliotecas não estão exclusivamente centradas na guarda e na disseminação da informação. A pesquisa objetivou verificar as necessidades de informação de uma categoria especifica de usuários, os 'usuários internos'. Identifica esta classe composta por profissionais atuantes nas bibliotecas universitárias, e que demandam informação para suas atividades laborais. Descreve a necessidade de informação para fins: práticos; profissionais e intelectuais. Analisa a tríade de finalidades nas quais, o 'usuário interno' busca e usa a informação. Metodologicamente esta pesquisa trata-se de um estudo de caso realizado na Biblioteca Central Zila Mamede/UFRN, com abordagem quanti/qualitativa, de natureza descritiva e exploratória, tendo como instrumentos de coleta de dados o questionário e a entrevista. Tem como sujeitos 18 "bolsistas de apoio técnico" da Biblioteca Central Zila Mamede/UFRN; a quem o fito da pesquisa é factual. Conclui-se que apesar de haver uma satisfação da busca do desempenho profissional destes usuários, é necessário que exista um fluxograma de atividades incluindo a rotatividade em tempo determinado. Sugere que na resolução da "bolsa de apoio técnico" tenham descritas as atividades dos "bolsistas" com exatidão para que tanto "bolsista" como a instituição que necessite do auxílio deste nas atividades, saibam suas reais atribuições.
\end{abstract}

PALAVRAS-CHAVE: Estudo de usuário. Necessidade de informação. Usuário interno. Competência informacional.

\begin{abstract}
Describes the search and use of information by users as one of the motivations to libraries to evolve the services it provides, adapting or restructuring its mission. It points out that currently the libraries are not exclusively focused on custody and dissemination of information. The research aimed to verify the information needs of a specific category of users, the 'insiders'. Identifies this class consisting of professionals working in university libraries, and requiring information for their work activities. It describes the need for information in the: practical; professionals and intellectuals. Analyzes the triad of purposes in which the 'internal user' search and use information. Methodologically this research it is a case study, the study has quantitative / qualitative approach, descriptive and exploratory, using as instruments of data collection the questionnaire and the interview. Its subject 18 "technical support fellows" of the Central Library Zila Mamede / UFRN; whom the aim of the research is factual. It concludes that although there is a satisfaction on the search of professional performance of these users, there needs to be an activity flowchart including turnover at times. Suggests that the resolution of "technical support fellows" has described the activities of "fellows" accurately so that both "fellows" as the institution which needs their assistance in the activities, know their real duties.
\end{abstract}

\footnotetext{
${ }^{1}$ Graduada em Biblioteconomia pela Universidade Federal do Rio Grande do Norte (UFRN). E-mail: micarllagomes@gmail.com

${ }^{2}$ Professora substituta do Departamento de Ciência da Informação na Universidade Federal do Rio Grande do Norte. E-mail: 1ynee21@gmail.com
}

Recebido em: 03/08/2014. Aceito em: 09/09/2015 
KEYWORDS: User study. Need for information. Internal User. Information literacy.

\section{INTRODUÇÃO}

Tendo como umas das finalidades a busca por informação as atividades laborais o relato que tem como base a monografia intitulada "Necessidades de informação e o 'usuário interno': o caso da Biblioteca Central Zila Mamede", em que se buscou responder ao questionamento sobre a necessidade de que fosse realizado um treinamento/capacitação para os "bolsistas de apoio técnico".

Para se chegar à consideração sobre possível treinamento aos "bolsistas de apoio técnico" que atuam como auxiliar de biblioteca, a pesquisa intencionou avaliar quais são as necessidades de informação dos 'usuários internos' diante das tarefas que lhe são atribuídas.

A avaliação será delineada através de objetivos específicos: a) Demonstrar os conhecimentos adquiridos anteriormente à efetivação na equipe de colaboradores da biblioteca; b) Descrever a função dos 'usuários internos' na biblioteca; c) Identificar a motivação da escolha em atuar como "bolsista de apoio técnico"; d) Descrever a necessidade de informação ao realizar as atividades que lhe são atribuídas;

Há estudos que tentam compreender os motivos que levam pessoas a realizarem a busca, uso e compartilhamento de informações. Pois, ainda que a busca ocorra de forma subjetiva, não é aleatoriamente que as pessoas buscam por informações. Esses estudos devem permitir a identificação de como as pessoas interagem com a informação obtida, desde o uso até o descarte.

É preciso que o profissional da informação tenha conhecimento dessa necessidade de informação (NI) e também da dificuldade por parte das pessoas em expressá-las. Nessa perspectiva, os estudos de usuários buscam compreender as reais necessidades informacionais das mesmas.

Desde a década de 1960, os trabalhos realizados na temática do estudo de usuários com foco na NI têm evoluído exponencialmente na área da ciência da informação. Os estudos não buscam somente entender os sistemas de acesso à informação, mas também as questões cognitivas dos usuários, buscando formas de conhecer cada vez mais os motivos que os levam a busca pela informação.

Nesse contexto, as pesquisas em estudos de usuários têm intenção de conhecer também quem são esses usuários que demandam a informação. Usualmente, para a ciência da informação, os usuários são entendidos como aqueles que utilizam as unidades de informação.

Com os estudos realizados sobre a necessidade de informação, tem-se chegado a um tipo especifico de usuários: o 'usuário interno'. Classe composta por profissionais que atuam em bibliotecas universitárias públicas e privadas, e que demandam informação para suas atividades laborais, ou seja, a informação é empregada para orientá-los a exercer sua profissão ou cargo ocupado na instituição. Dessa forma, admite-se a NI para fins: práticos; profissionais e intelectuais. 
A literatura voltada ao entendimento dos usuários tem descrito os motivos de sua escolha por determinada unidade de informação, sendo os mais considerados os tangíveis, que estão relacionados à estrutura física, equipamentos, aparência, etc.; e intangíveis que Silva e Rados (2002, p. 202) os descrevem como "o relacionamento do pessoal da biblioteca com os clientes". Este último, somente poderá ser percebido através do contato direto entre usuários e colaboradores.

Este estudo é fruto do arrolamento de informações referentes ao serviço prestado pela biblioteca universitária, que aborda o 'usuário interno' como o ser essencial na realização da prestação de serviço.

\section{SERVIÇOS DE INFORMAÇÃO E O USUÁRIO INTERNO}

A expressão "estudos de usuários" tem sido utilizada desde a década de 30, quando alguns estudiosos em pesquisas sobre comunicação se sentiram instigados a analisar o processo de transmissão da informação. Estes profissionais da comunicação inquietavam-se com os aspectos sociais da comunidade. Isso tornou valorativa a realização dos estudos de usuários, observando e questionando suas NI, como menciona Cruz (2008)

\footnotetext{
A expressão "estudo de usuários" apareceu em meados do século xx, no contexto das Ciências Sociais para observar ou questionar os usuários sobre suas necessidades, preferências, opiniões e avaliação a respeito dos serviços oferecidos ou em atividade de planejamento de produtos/serviços. (CRUZ, 2008, p.91).
}

Os estudos realizados até o ano de 65 consolidam a investigação sobre os usuários para o âmbito da biblioteca, mas sem gerar conhecimentos expressivos, para o termo das necessidades informacionais (NIs) dos usuários. Tal expressão carecia de uma nova compreensão, dessa vez para identificar quem são os usuários.

Para essa compreensão de quem é o usuário é preciso aceitar que o mesmo possuiu "fenômenos sociais de interação com outros seres que estimulam a consciência para construção de informação" (SILVA, 2012, p. 105), deixando entender que usuário é;

[...] aquele indivíduo que necessita de informação e a busca em um sistema de informação que tenha acesso e se beneficie com a mesma. Assim, os sistemas de informação devem ter um conhecimento preciso sobre seus usuários, suas necessidades, formas e fontes de busca e uso da informação. (ALMIRANTE; RAMALHO, 2007, p. 3).

A tecnologia do sistema de informação que tanto facilita as atividades de busca e recuperação da informação nas bibliotecas não será determinante para a escolha do usuário quanto ao uso do sistema. É preciso que haja relevância aos itens intangíveis à compreensão sobre usuários, pois, o "modo como as coisas serão realizadas é que será fator decisivo na escolha do serviço, no qual o usuário será conquistado" (BATPISTA; LEONARDT, 2011, p. $52)$.

Entendendo ainda que, não somente para os usuários, mas também para o profissional da informação, é preciso buscar por informação. Segundo os autores, 
[...] usar informação é trabalhar com a matéria informação para obter um efeito que satisfaça a uma necessidade de informação. O objetivo final de um produto de informação, de um sistema de informação deve ser analisado em termos dos usos da informação e dos efeitos resultantes desses usos nas ações dos usuários. (COSTA; SILVA; RAMALHO, 2009, p. 5).

A informação torna-se um objeto de consumo e sua procura é crescente, perpassando por processos: históricos e cronológicos; humanos; psicossociais; institucionais e pedagógicos (SILVA, 2012, p. 107) tornando imprescindível que as bibliotecas esbocem entendimento sobre como a informação transforma as ações de busca e uso da mesma por parte de seus usuários.

$\mathrm{Na}$ abordagem alternativa ou abordagem da percepção do usuário, como tem sido expressa na literatura, há a intenção de alterar as perspectivas dos estudos de usuários, pois aceita-os:

[...] como pessoas com necessidades cognitivas, afetivas e fisiológicas fundamentais próprias que operam dentro de esquemas que são partes de um ambiente com restrições socioculturais, políticas e econômicas. Essas necessidades próprias, os esquemas e o ambiente formam a base do contexto do comportamento de busca de informação. (FERREIRA, 1995, p. 6)

Percebe-se que os estudos de usuários cada vez mais se inquietam com as questões subjetivas do indivíduo, compreendendo-os como um ser único e de aspectos comportamentais distintos, mas que, "compartilha com os demais algumas características do sentido de tornar possível a interação e a comunicação entre os membros de um determinado grupo" (GUIMARÃES PIMENTA, 2012, p. 47), tornando possível sua categorização, para o entendimento da NI.

A abrangência na abordagem alternativa dos estudos de usuários intensifica as investigações com alusão ao comportamento e o progresso de suas competências ao buscarem por informação. $\mathrm{O}$ desenvolvimento desta abordagem alternativa dos usuários, implicará em compreendermos a importância que a informação pode ter na vida desse indivíduo e ajuda a entender o valor da informação na vida cotidiana das pessoas. (WILSON, 2006, p. 666).

Igualmente para o sistema de informação a compreensão acarretará em inovação, de modo "que sejam mais flexíveis no processo de busca de informação, considerando que as necessidades de informação de cada indivíduo são diferentes e mudam no decorrer do tempo" (CAVALCANTI, 2008, p. 18).

Nas palavras de Grogan (2001, p. 19) vemos que "a cada dia o mundo da informação se torna mais complexo, o usuário auto-suficiente parece mais do que nunca uma miragem" essas palavras evidenciam que os usuários tendo à disposição uma vasta quantidade de informações, terão mais dúvidas do que certezas, na sua busca independente. 
Incertezas que cada vez mais os levam a tomada de decisões sem ter a informação completa, assim como menciona Wilson (2006, p. 664) "muitas decisões são tomadas com informações incompletas" (Tradução nossa). Desse modo, o serviço de referência tem como competência realizar orientação aos usuários de forma especifica e humanizada, assim descreve o autor, Mesquita (2010).

\begin{abstract}
Das várias componentes do serviço de referência, destacam o contacto pessoal, a relação humana entre o profissional da informação e o leitor/ utilizador como as mais importantes. As definições do serviço enfatizam a importância da proximidade entre o utilizador e o profissional da informação no momento do atendimento. (MESQUITA, 2010, p. 29)
\end{abstract}

Assim como os usuários do sistema de informação, o bibliotecário precisa chegar ao estado satisfatório do conhecimento, tendo a diminuição de incertezas, decorrente da obtenção de informações do usuário. Isso garantirá, precisão na busca pela informação solicitada.

\title{
NECESSIDADES E COMPETÊNCIAS INFORMACIONAIS
}

O termo necessidade de informação ainda busca uma definição concretizada nos estudos dos usuários, para tanto, os termos têm sido usados de várias maneiras por pesquisadores em revisões bibliográficas e por vezes diferentes e incertos.

Necessidades, demandas e desejos usam-se de modo semelhante: todavia, estes termos não são idênticos. O conceito de necessidades de informação está encaixado nos estudos de usuários e de uso de fontes de informação que formam a mais extensa área de pesquisa em Biblioteconomia e Ciência da Informação. (BETTIOL, 1990, p. 61),

As atividades que ocasionam no usuário a carência de informação surgem das esferas pessoais e/ou profissionais, Bettiol (1990) menciona que é preciso reconhecer que essas necessidades nascem do papel que um indivíduo desempenha na sua vida social. Dessa forma, atribui-se que à medida em que o indivíduo "percebe a insuficiência ou inadequação dos conhecimentos necessários para atingir objetivos e/ou solucionar problemas" (MIRANDA, 2006, p. 106) ele reconhece sua necessidade de informação.

Ao realizar a busca e fazer o uso da informação, além de captar respostas satisfatórias, o usuário terá a percepção de uso do sistema de informação, portanto segundo Paisley ${ }^{3}$ (1968 apud BETTIOL, 1990, p. 62) terá as consequências "do uso da informação, isto é, produtividade". Numa outra situação em que ele perceba sua insuficiência ou inadequação do conhecimento para realizar alguma atividade, buscará novamente por informação e dessa vez terá habilidade em encontra-la.

\footnotetext{
${ }^{3}$ PAISLEY, W. J. Information needs and uses. Annual review of Information Science and Technology, 3:1-30; 1968.
} 
No cotidiano, as situações são diversas e isso torna dinâmico o ciclo da NI, favorecendo o desenvolvimento das competências informacionais. Pois embora haja a competência individual, em que existe um "conjunto de conhecimentos, habilidades e atitudes que cada pessoa possui” (MIRANDA, 2004, p. 116) a diversidade nas situações promove a busca distinta e com respostas específicas sobre o assunto.

Nessa esfera profissional é compreensível que a busca por informação seja demandada por pessoas que estão inseridas em atividades laborais. Portanto, sua NI é acurada, e normalmente inerente às suas atividades funcionais. Esse aspecto tem sido abordado dentro das perspectivas dos estudos de usuários, sendo fortemente aceitável que as atividades laborais promovam a incerteza na capacidade de realizá-las, pois mais que habilidade, é preciso conhecimento para fazê-lo.

\begin{abstract}
Por conseguinte, ao se pensar no profissional da informação como aquele formado apenas nas universidades, estará sendo excluída uma série de outros trabalhadores de nível médio, cujo aprendizado do trabalho informacional se dá na realização cotidiana de certas tarefas, de um modo geral, orientadas por outro trabalhador com formação universitária. (FERREIRA, 2006, p. 102)
\end{abstract}

Nessa categoria de usuários há uma heterogeneidade sociocultural de seus integrantes. A isso implica saber que "as necessidades [informacionais] nascem dos papéis dos indivíduos na vida social, e o mais relevante desses papéis é o papel exercido no trabalho" (MIRANDA, 2006, p. 103).

Na categoria do 'usuário interno' haverá uma distinta busca por informação, e que o emprego do conhecimento em suas atividades funcionais será determinante para a existência da NI. Mas a percepção de mundo que este 'usuário interno' possui, também influenciará no processo de busca da informação.

\title{
METODOLOGIA
}

Sendo esta pesquisa um estudo de caso que segundo Ventura (2007) “dá a oportunidade para que um aspecto de um problema seja estudado em profundidade dentro de um período de tempo limitado" (VENTURA, 2007, p. 385), realizado no âmbito da Biblioteca Centra Zila Mamede localizada na Universidade Federal do Rio Grande do Norte.

Descreve-se ainda a pesquisa "como procedimento racional e sistemático que tem como objetivo proporcionar respostas aos problemas que são propostos" (GIL, 2010, p. 1), esta pesquisa abordará segundos seus objetivos, a descrição de determinado fenômeno, através do acúmulo de informações obtidas na coleta de dados em campo. Essa pesquisa possui abordagem quanti/qualitativa, de natureza descritiva e exploratória.

\section{Campo de pesquisa: biblioteca central zila mamedel ufrn}

O campo de estudo para esta pesquisa é a Biblioteca Central Zila Mamede (BCZM) da Universidade Federal do Rio Grande do Norte (UFRN). A BCZM é formada 
hierarquicamente por: Direção; Conselho Supervisor; Assessoria Técnica; Secretaria Administrativa; cinco coordenadorias; dez setores e duas seções.

Para auxiliar no pleno funcionamento de suas atividades organizacionais a BCZM conta com o apoio de alunos, que vinculados à UFRN, atuam como "bolsista de apoio técnico". No total são 86 "bolsistas de apoio técnico" que a biblioteca dispõe no auxílio de suas atividades.

Hierarquizando os responsáveis pelo funcionamento das atividades na BCZM. Mesmo tendo como sujeito principal desta pesquisa o "bolsista", foi necessário colher informações dos chefes de setores: Informação e Referência Circulação, Coleções Especiais bem como da Diretoria da Instituição.

Refletindo sobre as palavras de Cunha (1982) a respeito da coleta dos dados realizada com usuários em que seja necessária "liberdade e tempo" e o não constrangimento "pela presença do entrevistador" (CUNHA, 1982, p. 8), optou-se pelo questionário como instrumento para coleta de dados com os "bolsistas", composto por questões dicotômicas e de perguntas abertas e fechadas. Já com os chefes e a diretoria foram realizadas entrevistas padronizadas.

\section{RESULTADOS E ANÁLISE DOS DADOS}

De um total de 86 "bolsistas" a pesquisa foi realizada com 18 desses "bolsistas" isso comtempla os $20 \%$ dos "bolsistas" que auxiliam no atendimento ao usuário externo na BCZM.

\section{Perfil dos sujeitos: os 'usuários internos'}

Para as atividades diárias na biblioteca serem e permanecerem eficientes, a biblioteca conta com o auxílio dos "bolsistas de apoio técnico". São alunos vinculados a instituição pública de ensino, como é o caso da UFRN. Se enquadram na categoria de beneficiários do programa de Assistência Estudantil da resolução no 169/2008 do Ministério da Educação. Segundo o parágrafo $4^{\circ}$ do artigo dessa resolução, a bolsa de apoio técnico tem como objetivo:

\footnotetext{
A bolsa de assistência estudantil na modalidade de apoio administrativo ou apoio técnico tem por objetivo contribuir com a permanência e o sucesso do aluno, oportunizando a inserção dos beneficiários em atividades institucionais que contribuam para sua formação profissional e cidadã, mediante o pagamento de contribuição monetária que ajude na manutenção do aluno e facilite a sua dedicação aos estudos. (BRASIL, MINISTÉRIO DA EDUCAÇÃO, 2008).
}

No caso da BCZM, estes alunos que atuam como "bolsista de apoio técnico" realizam as atividades de auxiliar de biblioteca e em especial aquelas atividades voltadas ao atendimento ao público. Essas atividades demandam informações para que sendo o serviço prestado como bolsista se tornem eficientes. 
Iniciando nossa análise do perfil dos "bolsistas" temos que quantitativamente, $44 \%$ dos "bolsistas", são construídos pelo gênero feminino e $56 \%$ do masculino, com idade entre 19 a $21(45 \%)$ e entre 23 a 25 anos (44\%). Percebemos que o corpo estudantil é composto por pessoas que ingressão cedo uma universidade, e que provavelmente não possuem experiência no mercado de trabalho, por se dedicarem aos estudos à nível superior.

A Quadro 1 indica que os cursos da área de Humanística II, ocupam significativamente o quadro de "bolsistas de apoio técnico" na BCZM, cerca de $61,11 \%$, seguido pelo de Tecnológica II com 22,22\%.

Acontece que na área de Humanística II, os cursos são realizados num único turno (manhã, tarde ou à noite) permitindo que o aluno tenha disponibilidade em outros turnos para desenvolver outras atividades, além de seus estudos.

QUADRO 1 - Demonstração da diversidade nos cursos dos "bolsistas".

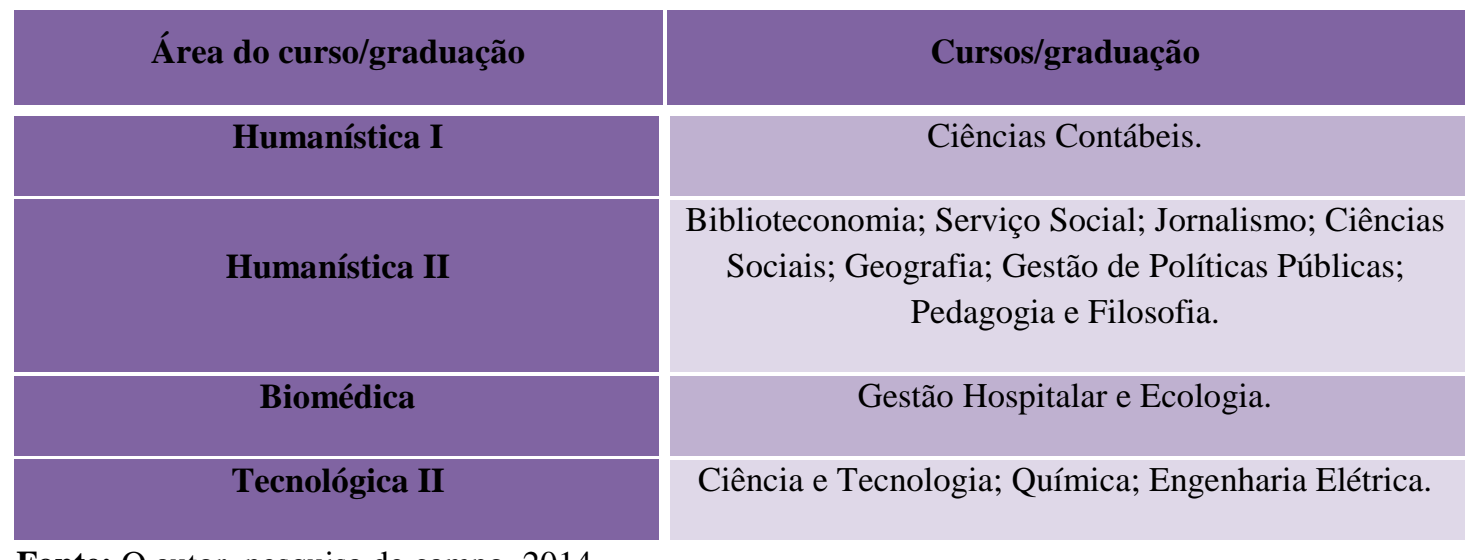

Fonte: O autor, pesquisa de campo, 2014.

Nas outras áreas, Humanística I, Biomédica e Tecnológica II, os cursos possuem aulas nos três turnos manhã, tarde e noite. Dessa forma o alunato da UFRN que faz parte das áreas citadas, satisfaz suas NIs, sobretudo, como aluno de graduação ou em outra situação especifica e não para realizar atividades administrativas na instituição.

Aprofundando-se nas questões do perfil dos "bolsistas", sobre seu histórico de ensino, se "Possui outra graduação?", temos como resposta temos cerca de 5,5\% deles afirmando que possuem outra graduação.

Contudo, na quinta questão perguntou-se: Antes de ingressar na universidade fez algum tipo de curso profissionalizante? Mesmo sendo a primeira graduação em outro momento já haviam buscado por realização profissional, cerca de $39 \%$ dos "bolsistas" buscaram outra profissão, enquanto que de $61 \%$ deles, não buscaram uma outra alternativa profissional, antes do ingresso na universidade.

\section{Competências funcionais}

Na primeira questão, observa-se que alguns alunos possuem compreensão das ações como "bolsistas de apoio técnico" e de profissionais focados no atendimento ao cliente/ 
usuário. Cerca de $22 \%$ deles já estiveram atuando em atividades profissionais, com tempo de permanência entre 1 ano à 4 anos.

Na sétima questão intencionou-se averiguar a motivação dos "bolsistas", partindo do princípio da escolha pelo local de atuação. Perguntou-se: O que o levou a buscar atuar como "bolsista de apoio técnico", no auxílio das atividades funcionais da BCZM? Com a média de $44 \%$ que buscam por auxílio financeiro e $28 \%$ que querem obter novos conhecimentos, fica evidente que o motivo financeiro e a busca por conhecimento, fortemente contribuem na decisão de ser "bolsista de apoio técnico".

Mas há motivo subjetivos que os levam à decisão de se tornarem "bolsistas". Descrevem a flexibilidade com $16 \%$ e o trabalho em equipe com $8 \%$, como motivos decisivos na escolha da BCZM para atuação como "bolsista". Verifica-se isso nas seguintes respostas:

Interação com o mais variado tipo de pessoas, o trabalho em equipe (SUJEITO D). [...] a comodidade de poder trabalhar e estudar no mesmo local (instituição) (SUJEITO L).

Identifica-se nessa questão a competência interpessoal, no aspecto subjetivo da interação com a comunidade acadêmica da UFRN, em que "os comportamentos humanos e os processos interpessoais, a empatia e a sensibilidade social, a habilidade de comunicação e a capacidade de cooperação" (MIRANDA, 2004, p. 116), definem a decisão de atuar como "bolsistas".

Pelos motivos descritos anteriormente, estes alunos atuarão como "bolsistas" provavelmente durante toda a graduação, dessa forma a oitava e a nova questão, avaliam o comprometimento deles no que se refere ao tempo e a quantidade de setores que já estiveram exercendo as atividades.

Verifica-se que o tempo de atuação do "bolsista" na BCZM sobressai com cerca de $39 \%$ deles atuando há menos de um ano; tem-se ainda respectivamente que $22 \%$ chegam ao tempo de mais de um ano ou mais de dois anos atuando com "bolsista". Isso confere a probabilidade de que, passem mais da metade da graduação, atuando na atividade remunerada como "bolsista de apoio técnico".

Embora apenas 33\% deles exerçam atividades em mais de um setor, e 66\% até então, realizaram ou realize atividades em um único setor, vemos que seu conhecimento fica restrito a dois setores em que frequentemente tenham exercido a função e portanto, adquirido competência. Quanto às ações desenvolvidas pelos "bolsistas", 95\% das respostas essá no atendimento ao usuário, como mostra o Gráfico 1. 


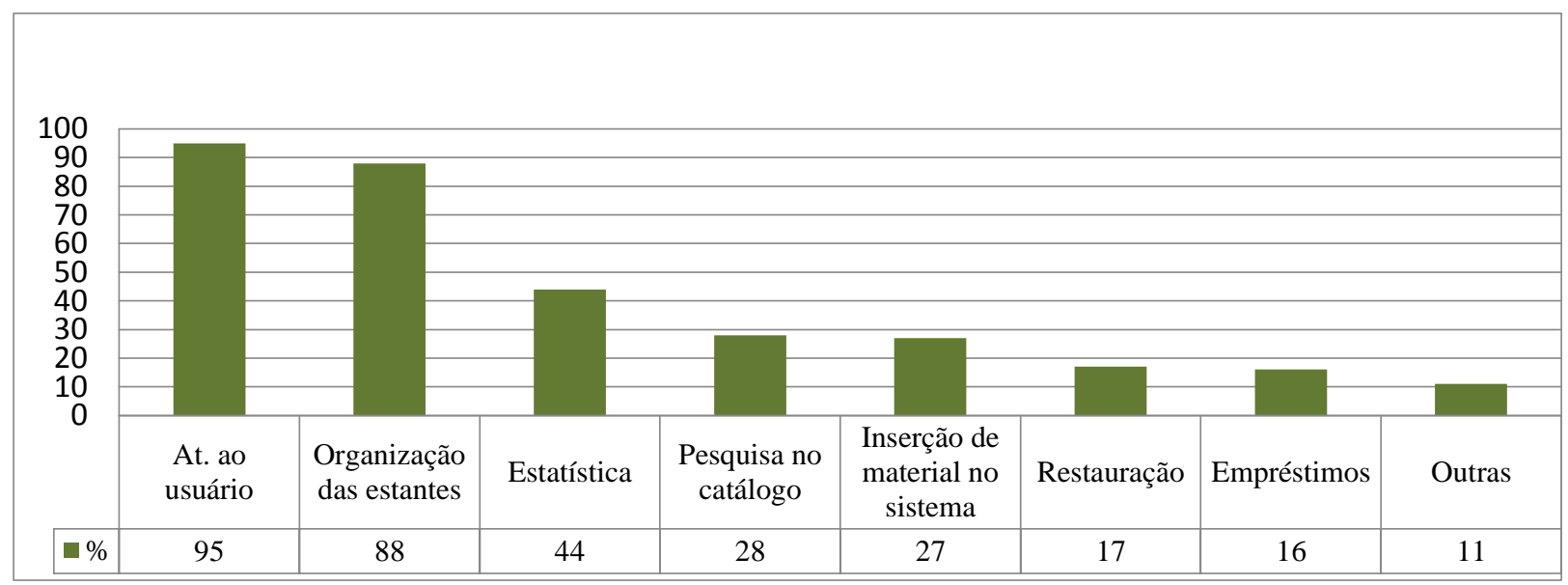

GRÁFICO 1 - Ações desenvolvidas pelos ‘usuários internos’ na BCZM.

Fonte: O autor, pesquisa de campo, 2014.

Inseridos no ambiente da biblioteca, os "bolsistas" possuem contato direto com os usuários, ficando sob sua responsabilidade o atendimento.

\section{Necessidade de informação}

Partindo da premissa de que é necessário um saber fazer para que as atividades laborais possam ser desenvolvidas, perguntou-se: $\mathbf{O}$ aprendizado obtido para exercer as atividades que lhe foram atribuídas, foi através de alguma capacitação/ treinamento? Tem-se como resposta que $44 \%$ dos "bolsistas" da BCZM tiveram um treinamento para realizarem suas atividades laborais, ficando cerca de $55 \%$ fora desse treinamento.

Sendo necessário verificar a satisfação dos "bolsistas" perguntou-se na décima segunda questão: Está satisfeito com as atividades que desenvolve? Dessa questão obtevese que $89 \%$ dos respondentes estão satisfeitos no desenvolvimento de suas atividades.

$\mathrm{Na}$ décima terceira questão, foram questionados sobre o nível de conhecimento da instituição, no caso a BCZM. Temos que $28 \%$ dos respondentes consideram seu conhecimento como Razoável e/ou Bastante, e 22\% como Suficiente. Vê-se que não há dificuldades na absorção das informações que lhes são transmitidas.

Finalizando a análise dos dados, perante os resultados obtidos através do questionário aplicado aos "bolsistas de apoio técnico" da BCZM, tem-se a questão sobre a possibilidade de participação em treinamento especifico sobre as atividades na instituição, caso a mesma promovesse. Cerca de $95 \%$ participariam.

Destarte, para o conhecimento dos "bolsistas" a biblioteca funciona como um laboratório em que as experiências, e a troca de informações lhes auxiliarão na formação profissional e também dará suporte para o desenvolvimento de suas habilidades. 


\section{Considerações das entrevistas}

Coordenadoria de apoio ao Usuário: Informação e Referência, Circulação e Coleções Especiais

Essa pesquisa fita analisar, sobretudo, as NI dos "bolsistas". Dessa forma, para a análise dos resultados nessa seção algumas respostas serão abordadas com intensidade em virtude de seu conteúdo ser valorativo aos objetivos da pesquisa.

$\mathrm{Na}$ entrevista realizada com chefes de alguns setores da Coordenadoria de apoio ao usuário, nota-se que eles, juntamente com a Diretora e Vice, possuem experiências como gestores. Já foram chefes dentro da própria instituição em outros setores ou mesmo estão há certo tempo chefiando o setor.

Embora o contato com os "bolsistas" em muitos momentos seja mais através de reuniões, na pergunta: Como você classifica seu relacionamento com os "bolsistas de apoio técnico?" as chefias classificam entre Bom e Satisfatório. Evidencia-se, o bom relacionamento em equipe, por parte dos entrevistados.

Para a pergunta: Em sua opinião, deveria haver algum pré-requisito para que o alunato da UFRN atue como "bolsista de apoio técnico" nessa biblioteca? São unânimes as respostas quanto à questão: em que se fosse criado esse pré-requisito o ideal é que os bolsistas cursassem biblioteconomia.

Na questão: Você considera pertinente que a instituição promova treinamento especifico, sobre as atividades internas, para o aluno atuar como "bolsistas de apoio técnico"? Eles advertem sobre o fluxo de entrada e saída desses "bolsistas", que não existe um período determinado, ocorrendo de forma aleatória. Na medida em que sair um, outro entrará. Então, no momento em que entra outro "bolsista" é feito com este uma visita técnica, sendo mencionadas as atividades do setor que ele ficará responsável e resumidamente os demais setores da biblioteca.

\section{Diretoria da BCZM}

Igualmente à análise anterior serão consideradas algumas questões. Analisando a partir da terceira e da quarta questões, pergunta-se sobre o relacionamento com os responsáveis e com os "bolsistas de apoio técnico", respectivamente, foi classificado como Bom. Embora o contato com os "bolsistas" seja mais por intermédio de reuniões.

Para a questão sobre o pré-requisito: Em sua opinião, deveria haver algum prérequisito para que o aluno atue como "bolsista de apoio técnico" nessa biblioteca? A diretoria considerou que o pré-requisito é algo que dependerá do setor, pois existem setores que realmente necessitam de um conhecimento mais especifico, como é o caso do setor de informática. Ainda assim sem o pré-requisito, do ponto de vista da diretoria, os "bolsistas" atuais estão realizando as atividades satisfatoriamente, até mesmo, acima da média. 
Quanto ao questionamento: Você considera pertinente que a instituição promova treinamento específico, sobre as atividades internas, para o aluno atuar como "bolsistas de apoio técnico"? A diretoria responde positivamente. Entretanto a realização de um treinamento e/ou capacitação para os "bolsistas" é algo difícil de realizar, pois há questão de datas, horários, fluxos de atividades, dentre outras situações adversas. Principalmente porque, quando se pensa em fazer este tipo de atividade normalmente é no período de férias.

Conclui-se esta análise determinando, que mesmo composta por heterogeneidade de pessoas e bem hierarquizada, a BCZM possui colaboradores entrosados e com entendimento sobre importância e permanência nas atividades de forma eficiente.

\section{CONSIDERAÇÕES FINAIS}

Com os resultados sobre os 'usuários internos', é entendido que a BCZM conta com uma equipe heterogênea, formada por alunos, que auxiliam nas suas atividades funcionais. Infere-se que ser "bolsista de apoio técnico" pode ser aceito como a primeira experiência profissional desses alunos que tão cedo ingressaram na vida acadêmica, sendo esta também a busca por uma formação à vida profissional. Torna-se claro que para exercer as atividades laborais necessitam estar preparados e ter consciência de suas atribuições.

Nessa pesquisa foi percebido que os "bolsistas" têm a percepção exata de sua responsabilidade, e que reconhecem sua importância no processo de transmissão da informação, tornando-a acessível para o usuário acolhido. Dessa forma, verifica-se que a necessidade de informação dos "bolsistas" da BCZM é instantânea, sendo facilmente detectada e portanto, precisamente elucidada.

A resolução 169/2008 que regulamenta a "bolsa de apoio técnico" intenciona contribuir com a permanência do aluno, dando a ele a oportunidade de atuar em atividades remuneradas e que contribuam para sua formação profissional. Entretanto, os alunos que optam por exercer atividades laborais, não buscam somente essa parcela de experiência profissional, eles buscam algo a mais.

Ao considerarem as atividades do seu cotidiano de fácil absorção, e juntamente com o auxílio de seus colegas veteranos, conseguem realizá-las com sucesso. Isso demonstra que os alunos estão cientes das atividades que devem desenvolver, e que buscam um conhecimento novo. Tendo a confiança de que este conhecimento irá auxiliá-los fortemente em questões profissionais, bem como pessoais.

Considera-se que esta pesquisa alcança através dos métodos apropriados, seus objetivos em analisar os aspectos subjetivos da necessidade de informação do "usuário interno". Tendo o amparo na literatura, e com a análise dos dados, foi possível encontrar abordagens sobre o processo de busca e uso da informação. 
Estes processos de busca e uso da informação propiciam ao indivíduo conhecimento na esfera profissional, mesmo aos que ainda não estejam atuando verdadeiramente como profissionais.

Deixa-se ainda a sugestão para que seja elaborado um fluxograma das atividades a serem desenvolvidas e com tempo de permanência dos "bolsistas" em determinado setor, pois foi verificado que a permanência do "bolsista" em um único setor não propicia o desenvolvimento de sua competência em relação às diversas atividades que por ele podem ser desempenhadas, lhe assegurando o "novo conhecimento". Sendo este o motivo que consideravelmente o leva a atuar como "bolsista de apoio técnico" na BCZM.

Em trabalhos realizados com usuários de sistema de informação, frisando as abordagens tradicionais ou alternativas, busca-se nas considerações finais, responder ao questionamento inicial. Entretanto, esta pesquisa não intenciona dar-se por encerrada, mesmo porque não seria isso algo possível. Portanto, sobre esta pesquisa e ao contexto apresentado, espera-se que ela integre novos ciclos de interesses para pesquisas da categoria de usuários apresentada e sejam provocadas calorosas discussões sobre a temática explanada.

\section{REFERÊNCIAIS}

ALMIRANTE, Corina Marques de; RAMALHO, Francisca Arruda. Busca e uso da informação: um estudo com os alunos do curso de administração da UFPB. Biblionline, João Pessoa, v. 3, n. 2, p. 1-8, jul./dez. 2007.

BAPTISTA, Michele Marques; LEONARDT, Michele Poleto Lesina. A qualidade dos serviços prestados e a satisfação dos usuários em uma Biblioteca Universitária. Bibl. Univ., Belo Horizonte, v.1, n.1, p. 50-59, jan./jun. 2011.

BETTIOL, Eugênia Maranhão. Necessidades de informação: uma revisão. Rev. Bibliotecon. Brasília, v. 18, n. 1, p. 59-69, jan./jun. 1990.

BRASIL. Ministério da Educação. Resolução no 169, de 2008. Dispõe sobre a instituição do programa de bolsas de Assistência Estudantil e regulamenta os procedimentos de concessão, acompanhamento e avaliação do impacto destas no desempenho acadêmico dos alunos beneficiários. CONSELHO DE ENSINO, PESQUISA E EXTENSÃO. Natal, RN, 02 dez. 2008 .

CAVALCANTI, Daniele Belmont de Farias. Usuários da informação: modelos de estudos sobre o comportamento de busca e uso da informação. 2008. 42 f. Monografia (Bacharelado) - Graduação em Biblioteconomia, Departamento de Biblioteconomia, Universidade Federal do Rio Grande do Norte, Natal/RN, 2008.

COSTA, Luciana Ferreira da; SILVA, Alan Curcino Pedreira da; RAMALHO, Francisca Arruda. (Re)visitanto os estudos de usuários: entre a "tradição" e o "alternativo".

DataGramaZero - Revista de Ciência da Informação, v.10, n. 4, ago. 2009. 
CRUZ, Fernando William. Enfoques para Estudos de Usuários. In.: . Necessidade de informação musical de usuários não especializados. 2008. 325p. Tese (Doutorado em Ciência da Informação) - Faculdade de Economia, Administração, Contabilidade e Ciência da Informação, Universidade de Brasília, Brasília/DF. Cap. 3, p. 90-104.

CUNHA, Murilo Bastos da. Metodologias para estudo dos usuários de Informação cientifica e tecnológica. Rev. Bibliotecon. Brasília, v. 10, n. 2, p. 5-19, jul./dez. 1982. Disponível em:< http://bogliolo.eci.ufmg.br/downloads/CUNHA_1982.pdf $>$. Acesso em: 02 set. 2015.

FERREIRA, Sueli Mara Soares Pinto. Novos paradigmas e novos usuários de informação. Ciência da Informação, v. 25, n. 2, 1995. Disponível em: <http://revista.ibict.br/ciinf/index.php/ciinf/article/view/440/398>. Acesso em: 02 set. 2015.

FERREIA, Rubens da silva. Auxiliares de biblioteca e trabalho informacional: desafios e possibilidades para o Sibi/UFPA. Ci. Inf., Brasília, v. 35, n, 1, p. 102-114, jan./abr. 2006.

GIL, Antonio Carlos. Como elaborar projetos de pesquisa. 5. ed. São Paulo: Atlas, 2010. $184 \mathrm{p}$.

GROGAN, Denis Joseph. Serviço de referência. In.: A prática do serviço de referência. Brasilia: Briquet de Lemos, 2001. 196 p. Cap. 1. p. 7-35.

GUIMARÃES PIMENTA, Shirley. Conceitos de informação e texto nas abordagens do ponto de vista cognitivo na ciência da informação e do processamento da informação na psicologia cognitiva: uma visão interdisciplinar. Enc. Biblio: R. Eletro. Bib. Ci.Inf., Florianópolis; Santa Catarina, v. 17, n. esp. 1, p. 20-66, 2012.

MESQUITA, Alberto Gonçalves. Definição de serviço de referência: abordagem teórica. In.: Serviços de referência: do tradicional ao digital nas bibliotecas dos Institutos

Politécnicos públicos em Portugal. 2010. 86 f. Dissertação (Mestrado em Informação, Comunicação e Novos Media) - Faculdade de Letras, Universidade de Coimbra, Coimbra/Portugal. Cap. 3.1. p. 29. Disponível em: <https://estudogeral.sib.uc.pt/bitstream/10316/14812/4/Servi\%C3\%A7os\%20de\%20Refer\%C 3\%AAncia\%20nas\%20Bibliotecas \%20dos\%20Institutos\%20Polit\%C3\%A9cnicos_Alberto \%20Mesquita.pdf>. Acesso em: 02 set. 2015.

MIRANDA, Silvânia Vieira. Identificando as competências informacionais. Ci. Inf., Brasília, v. 33, n. 2, p. 112-122, maio/ago. 2004.

MIRANDA, Silvânia Vieira. Como as necessidades de informação podem se relacionar com as competências informacionais. Ci. Inf., Brasília, v. 35, v. 3, p. 99-114, set./dez. 2006.

SILVA, Chirley Cristiane Mineiro da; RADOS, Gregório Jean Varvakis. Gestão de serviços em bibliotecas: melhoria com foco no cliente. Revista ACB, Florianópolis, v. 7, n. 1, p. 198-218, 2002. Disponível em: <http://revista.acbsc.org.br/index.php/racb/article/viewArticle/370 >. Acesso em: 13 out. 2015. 
SILVA, Jonathas Luiz Carvalho. Necessidades de informação e satisfação do usuário: algumas considerações no âmbito dos usuários da informação. InCID: R. Ci. Inf. e Doc., Ribeirão Preto, v. 3, n. 2, p. 102-123, jul./dez. 2012.

VENTURA, Magda Maria. O estudo de caso como modalidade de pesquisa. Rev. SOCERJ, v. 20, n. 5, p. 383-386, set./out. 2007.

WILSON, T. D. On user studies and information needs. Journal of Documentation, v. 62, n. 6, p. 658-670, 2006. Disponível em:

<http://www.emeraldinsight.com/doi/full/10.1108/00220410610714895>. Acesso em: 01 set. 2015.

Como citar este documento:

GOMES, Micarla do Nascimento; ARAÚJO, Claudialyne da Silva. Serviços de informação e o 'usuário interno': necessidades de competências informacionais. Revista Digital de Biblioteconomia e Ciência da Informação, Campinas, SP, v. 13, n. 3, p. 579-593, set. 2015. ISSN 1678-765X. Disponível em: <http://periodicos.sbu.unicamp.br/ojs/index.php/rdbci/article/view/8639489>. Acesso em: 18 Set. 2015. 